\title{
Unusual injury? Recent injury in normal children and children with suspected non-accidental injury
}

\author{
D M ROBERTON, P BARBOR, D HULL
}

\begin{abstract}
Four hundred normal children aged between 2 weeks and 11 years were examined to determine the prevalence and site of recent injury of any type. There was evidence of injury in $37 \%$ with a steady increase in prevalence to $60 \%$ by the end of the third year of life. Bruising of the hands and feet and of the lower legs was the most frequent type of injury. Head and facial injuries were most common between 18 months and 3 years (17\% of children) but were rare at other ages. Injury to the lumbar region was unusual before 5 years but was present in $14 \%$ of children of school age. In 84 children of similar age where non-accidental injury was proved or suspected a different pattern of injury was present. Sixty per cent had injuries to the head and face; this increase in prevalence was seen at all ages. These children also had more frequent injuries in the lumbar region, particularly before the age of 5 years.
\end{abstract}

\section{Introduction}

Child abuse was recognised only in its most obvious form in the late 1940s. Publicity from workers such as Caffey ${ }^{1}$ and Kempe et $a l^{2}$ led to the recognition that some apparently accidental injuries were inflicted by people who were caring for the child, often the parents. Now efforts are made to identify children at risk with the hope that long-term support for such families will avoid

\footnotetext{
Department of Child Health, University Hospital, Nottingham NG7 2UH

D M ROBERTON, MD, FRACP, paediatric registrar

P BARBOR, FRCP, consultant paediatrician

D HULL, FRCP, professor of paediatrics
}

serious injuries. With greater professional and public awareness of the problem the index of suspicion has increased in all those concerned with children, whether they be medical staff, nursery aides, school teachers, or concerned neighbours. One of the medical responsibilities is to decide whether the injuries in a particular child are consistent with the child's age, level of activity, and the proffered explanation for the injury. ${ }^{3}$ For severe injuries such as fractures, head injury, or burns the decisions are usually straightforward; for multiple minor injuries of varying ages the distinction between expected and improbable is more difficult to make, and there are very few guidelines. ${ }^{4}$

At any time many children when examined carefully have some evidence of minor trauma consistent with normal activity. ${ }^{5}$ Bruising to the front of the lower legs is known to be particularly common, injuries to the head and face are thought to be less common, while bruising over the lumbar spine has been thought to be suggestive of inappropriate injury. We performed a study to document the site and age distribution of injuries due to minor trauma in normally healthy children. The nature of these injuries was then compared with those experienced by children thought to have suffered from non-accidental injury.

\section{Method \\ NORMAL CHILDREN}

Recent minor traumatic lesions were sought in children attending routine child health and school clinics for routine nursery and primary school medical examinations from January to October 1981. All visible bruises, abrasions, and lacerations resulting from injuries received within the preceding two weeks were recorded on burns charts, as well as any evidence of more major injury such as burns or fractures. Scars from old wounds, infections, and burns were ignored, as were iatrogenic injuries (mainly lesions due to immunisation procedures). When possible an explanation was sought for all injuries.

The children were aged 2 weeks to 11 years and came from the socioeconomically disadvantaged central Nottingham area, where a 
high proportion of heads of families are unskilled or unemployed. Parents did not have advance knowledge of the recording procedure as they had brought their children for routine medical assessments at the request of the various clinics. All children were examined undressed, and recording was performed on one occasion only by the same paediatrician.

\section{CHILDREN SUSPECTED OF NON-ACCIDENTAL INJURY}

Casualty and hospital inpatient records for children aged 2 weeks to 11 years were reviewed for the period January to October 1981 . Details of injuries were recorded routinely on burns charts. All children included had suffered from admitted non-accidental injury or likely non-accidental injury-that is, a pattern of injury thought to be considerably at variance with the stated cause.

\section{Results}

NORMAL CHILDREN

Of the 400 normal children examined during the 10-month survey period, $148(37 \%)$ had a detectable lesion due to recent minor trauma. Bruises were the most common form of injury, often accompanied by minor abrasions or lacerations. Burns were recorded in only three children and were attributable to minor accidents; none had sustained recent fractures.

Fig 1 shows the distribution of injury in relation to age for the $\mathbf{4 0 0}$ children and the age distribution for selected sites of injury.
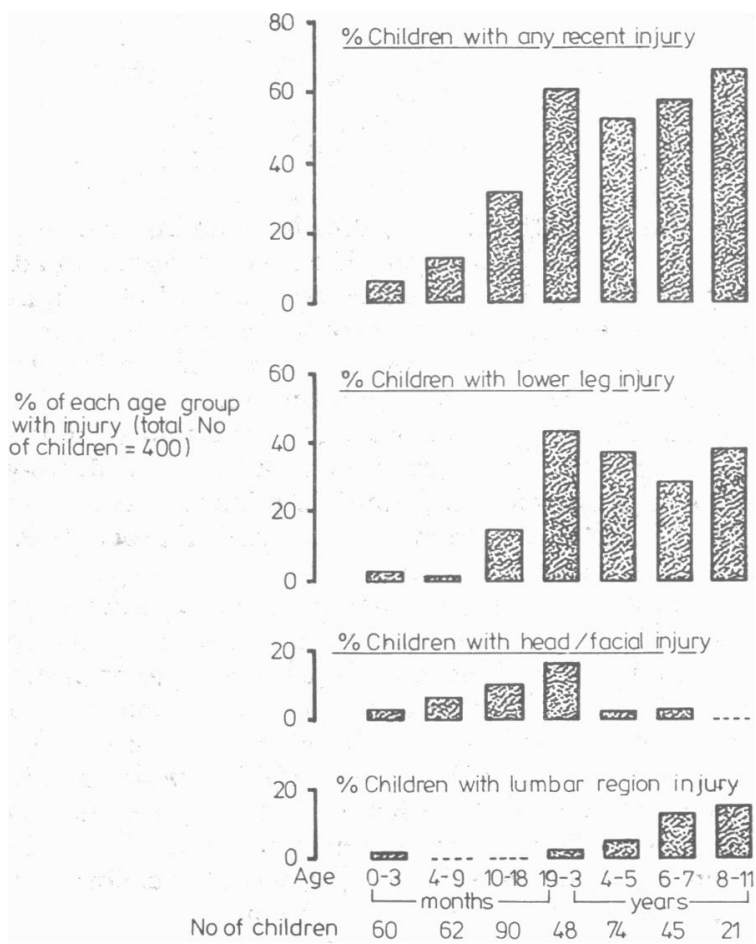

FIG 1-Distribution of injury with respect to age in 400 normal children.

Only four out of 60 children aged 2 weeks to 2 months had noniatrogenic injury (two further children had BCG immunisation abscesses). Two had injuries to the head and neck, one from a dog bite and one after a fall from a pram. One had unexplained bruising on the chest and one leg, and one baby of 4 weeks had unexplained abrasions over the lumbar spine. Bruising or other lesions remained uncommon in the 62 children examined between the ages of 3 and 9 months, with only one in eight children showing any evidence of injury. There was then a steady increase until the age of 3 years, with $50-65 \%$ of children in the age groups 18 months to 11 years having lesions, usually minor bruising.
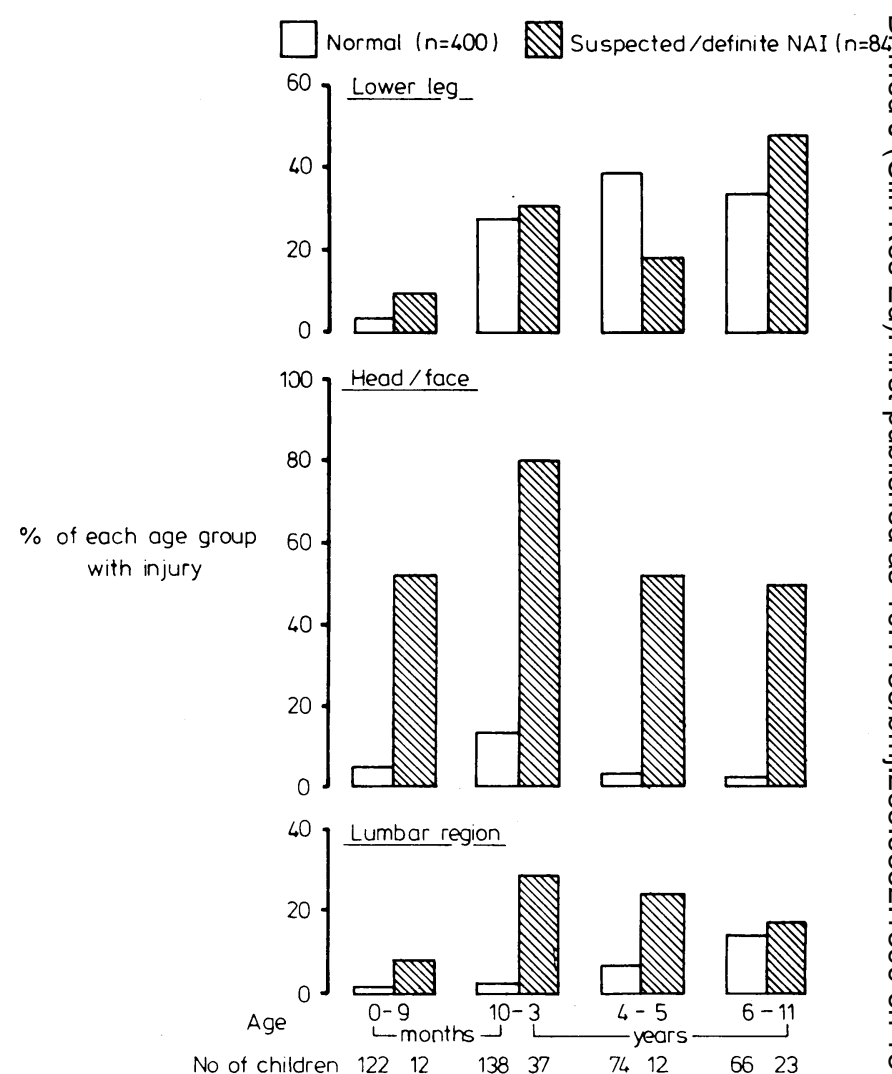

FIG 2-Injury at specified sites with respect to age in 400 normal children and 84 children with suspected or definite non-accidental injury (NAI).

Bruising of the hands and feet was the most common type and site of injury. Injuries to the lower leg, especially bruising over the anterior tibial surfaces, were most frequent in children between the ages of 180 months and 3 years and were present at the examination in $34.3 \%$ of all children of nursery or school age (fig 1). The next most commono sites were thighs or buttocks, or both $(17.0 \%$ of children over $18 \hat{\text { a }}$ months), and arms (15.4\% of children over 18 months). In contrast, injuries were present at each of these sites in only $2.4 \%$ of children under 18 months old.

Head and facial injuries, usually in the form of bruises or abrasions were relatively uncommon at all ages. The peak prevalence was between 18 months and 3 years with one in six children being affected, while such injury was rare before 9 months and after 3 years (fig 1). Injury to the lumbar region was seen in only two children out of 260 under 3 at the time of examination. Such injury, usually bruising, then became more prevalent with increasing age, with $14 \%$ of school-age children having lesions in this area (fig 1).

Injuries to the chest and upper back were uncommon, with a maximum incidence of $5 \%$ in any of the seven age groups. Only two children had injuries to the genitalia; one had vulval bruising after a응 "missed pot-sit" and one had testicular bruising having been kickedn during play.

\section{CHILDREN SUSPECTED OF NON-ACCIDENTAL INJURY}

During the ten-month survey period 119 children aged 2 weeks too 11 years attending hospital emergency or admitting services were examined for alleged or suspected non-accidental injury. Such injury was admitted for 35 children and was considered likely for 49 childrens in that the pattern of injury was greatly at variance with the stated cause. Of these 84 children, $44 \%$ were aged 9 months to 3 years. Most came from the central Nottingham area.

Injuries of all types and sites except the lower legs were much more common in these children than in the 400 normal children (table I) with the great majority of injuries being relatively minor. Ten per cento had sustained fractures; these children were usually under 1 year old $\cap$ One child had subdural haemorrhages and cerebral damage. Most burns were minor. Injuries to the head and face were particularly 
common and were seen with considerably increased prevalence at all ages when compared with the normal children (fig 2). Injury to the lumbar region differed in age distribution in comparison with normal children, being much more common between 9 months and five years. In contrast, injury to the lower legs did not differ significantly with age in the two groups.

Injuries of specified sites and type in 400 normal children and 84 children with suspected/definite non-accidental injury (NAI), ages 0-11 years

\begin{tabular}{lcc}
\hline & \multicolumn{2}{c}{$\%$ with injury } \\
\cline { 2 - 3 } Site/type of injury & $\begin{array}{c}\text { Normal children } \\
(\mathrm{n}=400)\end{array}$ & $\begin{array}{c}\text { Suspected/definite NAI } \\
(\mathrm{n}=84)\end{array}$ \\
\hline Head and face & 6.5 & 59.8 \\
Chest & 1.5 & 12.6 \\
Upper back & $2 \cdot 0$ & 11.5 \\
Arms & 8.5 & 38.1 \\
Lumbar region & 3.75 & 21.4 \\
Thigh and buttocks & $9 \cdot 25$ & 41.7 \\
Lower legs & 21.5 & 28.7 \\
Fracture(s) & 0 & 10.3 \\
Burn(s) & 0.75 & 11.3 \\
\end{tabular}

\section{Discussion}

Injury due to recent minor trauma is common in all children. This survey shows that such injury is likely to be detectable in some form in $37 \%$ of a group of normal children aged 2 weeks to 11 years at a single random examination. There is also a definite variation of prevalence and site of injury with age. Injuries of any type are uncommon before 9 months, with a steady increase to a plateau at 3 years. Lesions of the lower leg are found in most children aged over 18 months and have little importance but are uncommon before 9 months. Accidental head and facial injuries are most common in the active toddler and pre-nurseryage child but then become rare in older children, probably with the development of better co-ordination and protective skills. Injuries to the lumbar region are virtually not seen before 3 years but become more common in the older child, who is more likely to play with groups of children.

The children in the survey came from a relatively disadvantaged inner city area that has more crowded living conditions and a greater average family size where minor injury may be more likely than in other circumstances. Nevertheless, they form a useful group for comparative purposes when non-accidental injury is studied, as such children are also more likely to come from disadvantaged inner-city areas. ${ }^{6}$ ?

Features of the children injured by non-accidental means in this study are similar to those of other reports. Of the 84 children in whom such injury was admitted or thought highly likely, burns were seen in $10.3 \%$ and fractures had been sustained in $11.3 \%$, figures similar to those in the most recent review of the National Society for the Prevention of Cruelty to Children (NSPCC) special unit registers $\left(9.5 \%\right.$ and $11.1 \%$ respectively). ${ }^{8}$ The age distribution for burns and fractures was also similar to that of NSPCC register findings, with fractures being much more common in infants and burns occurring most commonly from 1 to 4 years of age. Head and facial injuries were particularly common at all ages in the children suspected of nonaccidental injury, a finding similar to those of previous British studies. ${ }^{6}{ }^{7}$ In contrast, such injury was rare in the normal children before 9 months or after 3 years of age. Injuries to the lumbar region appear to carry special significance in children before the age of 5 years, when they are rare in the normal child. In contrast, the normal school-aged child often has such lesions. In this latter age group injury to the lumbar region appeared to be of little importance in distinguishing likely non-accidental injury.

It should be noted that one paediatrician examined the first group of normal children prospectively, while several different doctors were responsible for recording the examination of the non-accidentally injured group, the case notes and diagrams being examined retrospectively by the same paediatrician. The groups were therefore different, and this could have resulted in underreporting of minor bruises in the injured group. As the junior doctors are encouraged to record all bruises on the burns charts, bruises on the face or back are unlikely to have been omitted.

Non-accidental injury often cannot be diagnosed according to readily defined criteria, particularly in areas where value judgments delineating appropriate or inappropriate levels of care and administered punishment vary according to socioeconomic, educational, and cultural background. This is especially true when non-accidental injury is moderate rather than severe, a trend noted in recent years. ${ }^{8}$ Often the doctor is asked to determine whether multiple minor injuries at various sites are compatible with normal activity and a normal level of care in young children. The prevalence and site of injury will vary with age; this study serves to give some guidelines for comparison at different ages and shows the altered pattern and distribution of lesions in children with actual or probable non-accidental injury.

\section{References}

1 Caffey J. Multiple fractures in the long bones of infants suffering from chronic subdural hematoma. American fournal of Roentgenology $1946 ; 56: 163-73$.

${ }^{2}$ Kemple CH, Silverman FN, Steele BF, Droegemueller $W$, Silver HK The battered-child syndrome. $\mathcal{F} A M A$ 1962;181:17-24.

${ }^{3}$ Smith BD. Current pediatric roles in child abuse and neglect. $A m \mathcal{F} D i s$ Child 1979;133:691-6.

${ }^{4}$ Anonymous. Child abuse: the swing of the pendulum. $\mathrm{Br} \mathrm{Med} \mathcal{F} 1981$; $283: 170$.

${ }^{5}$ Keen JH. Normal bruises in pre-school children. Arch Dis Child 1981 ;56: 75.

${ }^{6}$ Sills JA, Thomas LJ, Rosenbloom L. Non-accidental injury: a two-year study in central Liverpool. Dev Med Child Neurol 1977;19:26-33.

7 Smith SM, Hanson R. 134 battered children: a medical and psychological study. $\mathrm{Br}$ Med $\mathcal{F} 1974$;iii:666-70.

${ }^{8}$ Creighton SJ. Child victims of physical abuse, 1976. London: National Society for the Prevention of Cruelty to Children, 1980. (Third repert of the findings of NSPCC Special Units' registers.)

(Accepted 27 August 1982)

\section{Clinical curio: Dependence on Jeyes' fluid}

Mrs J M was referred for psychiatric consultation after an overdose of Tranxene (chlorazepic acid). She was severely depressed at the time of admission and could not stop crying. During the interview she revealed that she had been drinking Jeyes' fluid, a common gardening aid and household disinfectant, every day for the past two years. She was tempted to drink it initially because of the pleasant smell of diluted Jeyes' fluid, and she developed the habit of adding about three teaspoonfuls of the liquid to a cup of water and drinking this mixture two to three times daily. She felt this gave her energy to keep going. If she omitted to drink it she became listless and sad. Eventually she appeared to become addicted to it because she felt she was totally unable to cope without it. This craving suddenly subsided when she became pregnant, and she developed an aversion to the fluid even before she knew she was pregnant. When she stopped drinking the mixture she developed depressive symptoms over the ensuing four weeks to the point of attempting suicide. She was admitted to a psychiatric hospital but was not given any drug treatment because of her pregnancy. The symptoms of depression cleared in 10 days, and she was discharged. At follow-up one month later she was very well, and she has had no further desire for the liquid. None of the constituents of Jeyes' fluid are dependence forming. Its lethal dose (LD 50, oral, in rats) is $3.2 \mathrm{mg} / \mathrm{kg}$ body weight. It does not seem to have ill effects in small diluted doses although an acute overdose may cause severe gastrointestinal symptoms. The manufacturing company has received reports of people who took a teaspoonful of Jeyes' fluid as an aid to good health.- $L \mathrm{~K}$ HANNIFFY, chief psychiatrist, and s SHRIKHANDE, acting consultant psychiatrist, Portlaoise, Eire. 